\title{
PENYELIDIKAN DAN PERBAIKAN BANGUNAN MIRING \\ (Studi Kasus Struktur \\ Bangunan Rumah Tinggal di Kotabaru)
}

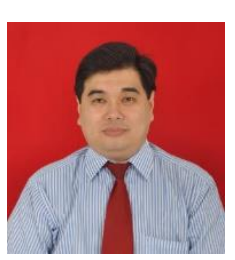

\section{Darmansyah Tjitradi}

Penulis adalah staff pengajar Program Studi Program Profesi Insinyur Universitas Lambung Mangkurat. Bidang keahlian penulis adalah teknik struktur khususnya struktur beton bertulang, modelling komputer struktur bangunan, dan assesment keruntuhan bangunan. buletinppi@ulm.ac.id

\section{Pendahuluan}

Bangunan Rumah Tinggal bertingkat 2 yang sekarang didiami oleh Bapak Gunadi dan Bapak Heriyanto dibangun pada tahun 1995 berukuran $8 \times 30 \mathrm{~cm}$, bangunan tersebut struktur utamanya terbuat dari Kayu Ulin dengan ukuran $17 \times 17 \mathrm{~cm}$ dan balok $6 \times 12 \mathrm{~cm}$ dengan lantai dasar dilapisi keramik $30 \times 30$ dan lantai 1 yang terbuat dari papan kayu ulin, dan dinding terbuat dari bata 2 tingkat, serta struktur atap terbuat dari kayu ulin dan penutup atap dari genteng metal. Kemudian kolom dilapisi dengan beton bertulangan utama dan geser sehingga menjadi berukuran 40x40 cm (lihat Gambar 1). Pada tahun 2007 orang ke-3 Toko Harapan Jaya yang yang bersebelahan dengan rumah Bapak Heriyanto membangun ruko yang terbuat dari struktur beton bertulang tingkat 3 dengan ukuran bangunan $8 \times 30 \mathrm{~m}$. Setelah itu pada awal tahun 2009 bangunan rumah Bapak Gunadi Utomo dan Bapak Heriyanto mengalami retak-retak dan mengalami kemiringan dan penurunan bangunan. Sehubungan dengan permasalahan tersebut diatas, maka perlu dilakukan pemeriksaan dan pengkajian terhadap bangunan tersebut, agar dapat disimpulkan seberapa jauh pengaruh kemiringan dan penurunan terhadap kondisi bangunan.

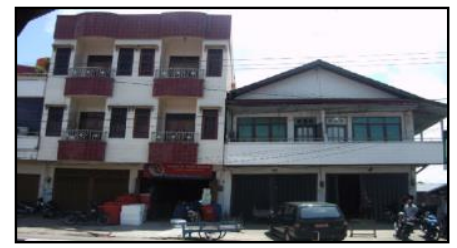

Gambar 1. Dari kiri Bangunan Rumah Tinggal Bapak Heriyanto dan Bapak Gunadi
Tulisan ini merupakan hasil dari penyelidikan bangunan miring yang mengambil kasus rumah tinggal di Jln. P.I. Kesuma Jaya No.14 Kotabaru yang bangunannya mengalami kemiringan dan pondasinya mengalami perbedaan penurunan. Penyelidikan yang dilakukan menggunakan cara pengamatan visual (kualitatif) yang merupakan pengamatan awal sebelum dilanjutkan dengan pengukuran secara kuantitatif melalui pengukuran kemiringan dan penurunan bangunan.

Dari hasil dari penyelidikan dapat diketahui bahwa tingkat kerusakan struktur bangunan masih dalam kategori ringan, sehingga masih dapat dilakukan perbaikan atau perkuatan terhadap struktur bangunan. Kata kunci: bangunan miring

www.buletinppi.ulm.ac.id

Tujuan dan manfaat dari pemeriksaan bangunan ini adalah:

1) Untuk mengetahui penyebab kemiringan dan penurunan bangunan

2) Untuk memberikan penilaian terhadap kondisi bangunan

3) Untuk memberikan rekomendasi perbaikan yang dapat digunakan untuk mengambil keputusan mengenai kelayakan bangunan, sehingga pihak pemilik dan pelaksana perbaikan bangunan dapat bekerja dengan ketelitian tinggi dan tingkat keamanan yang lebih pasti.

\section{Hasil Kerja}

\section{Pengukuran Kerusakan di Lapangan}

Pengukuran tingkat kerusakan bangunan dapat dibagi menjadi 2 bagian, yaitu:

1) Pengukuran Kualitatif, dilakukan dengan pengamatan visual dilapangan terhadap kerusakan komponen bangunan.

2) Pengukuran Kuantitatif, dilakukan dengan pengukuran kemiringan bangunan dengan alat Auto Levelling Sinar Laser Sincon SL-2, dan pengukur jarak Sinar Laser Rangefinder Bosch DLE-70 (lihat Gambar 2). 


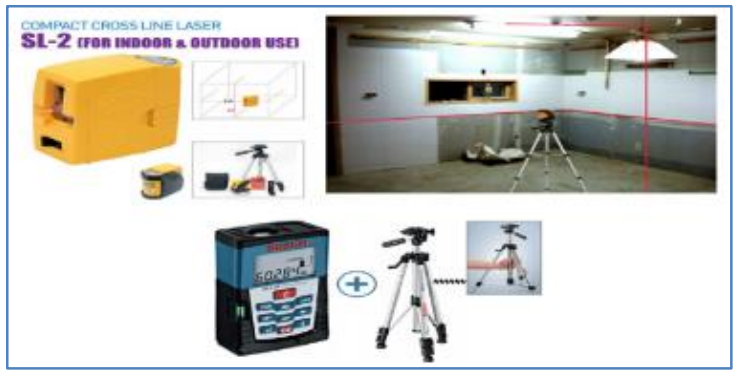

Gambar 2. Alat Auto Levelling SL-2 dan Laser Rangefinder Bosch DLE-70

\section{Tingkat Kerusakan Komponen Struktur Bangunan}

Tingkat kerusakan dari suatu struktur bangunan dapat ditentukan dengan pengamatan visual dilapangan dengan klasifikasi sebagai berikut (lihat Tabel 1 sd. 4):

Tabel 1. Tingkat Kerusakan Komponen Struktur Beton (Sjafei Amri, 2006)

\begin{tabular}{|c|c|}
\hline Tingkat Kerusakan & Deskripsi Kerusakan Komponen Struktur \\
\hline \multirow{2}{*}{$\begin{array}{c}1 \\
\text { (Rusak Sangat } \\
\text { Ringan) }\end{array}$} & $\begin{array}{l}\text { Retak rambut di permukaan beton terlihat dari jarak tidak terlalu jauh } \\
\text { (lebar retak }<0,2 \mathrm{~mm} \text { ) }\end{array}$ \\
\hline & $\begin{array}{l}\text { Tidak ada kerusakan struktur, terjadi kerusakan komponen arsitektur } \\
\text { dalam jumlah cukup }\end{array}$ \\
\hline \multirow{2}{*}{$\begin{array}{c}\text { "I } \\
\text { (Rusak Ringan) }\end{array}$} & $\begin{array}{l}\text { Retak rambut di permukaan beton terlihat dengan pengamatan visual } \\
\text { (lebar retak kira-kira } 0,2 \mathrm{~mm} \text { sd. } 1,0 \mathrm{~mm} \text { ) }\end{array}$ \\
\hline & $\begin{array}{l}\text { Kerusakan struktur ringan, meskipun komponen arsitektur mengalami } \\
\text { kerusakan signifikan. }\end{array}$ \\
\hline \multirow{3}{*}{$\begin{array}{l}\text { III } \\
\text { (Rusak Sedang) }\end{array}$} & Selimut beton hancur di sebagian tempat \\
\hline & Retakan besar meluas (lebar retak 1 s.d. $2 \mathrm{~mm}$ ) \\
\hline & $\begin{array}{l}\text { Terlihat kerusakan berat struktur, terjadi deformasi permanen antar } \\
\text { tingkat dengan kemungkinan keruntuhan kecil }\end{array}$ \\
\hline \multirow{3}{*}{$\underset{\text { (Rusak Berat) }}{\text { IV }}$} & Selimut beton hancur dalam jumlah besar dan baja tulangan terlihat \\
\hline & Selimut beton mengelupas (Spalling) \\
\hline & $\begin{array}{l}\text { Sebagian besar rangka bangunan rusak, deformasi permanen struktur } \\
\text { dapat menyebabkan keruntuhan }\end{array}$ \\
\hline \multirow{5}{*}{$\begin{array}{c}V \\
\text { (Runtuh/ Guling) }\end{array}$} & Baja tulangan tertekuk \\
\hline & Beton pada inti penampang hancur \\
\hline & $\begin{array}{l}\text { Deformasi pada kolom dan dinding terlihat (kemiringan > 6/100 rad } \\
\left(3,44^{\circ}\right)\end{array}$ \\
\hline & Settlement dan atau inklinasi pada lantai terlihat \\
\hline & $\begin{array}{l}\text { Keseluruhan gedung runtuh atau terguling, atau salah satu tingkat } \\
\text { runtuh }\end{array}$ \\
\hline
\end{tabular}

Tabel 2. Tingkat Kerusakan Komponen Struktur Baja (Sjafei Amri, 2006)

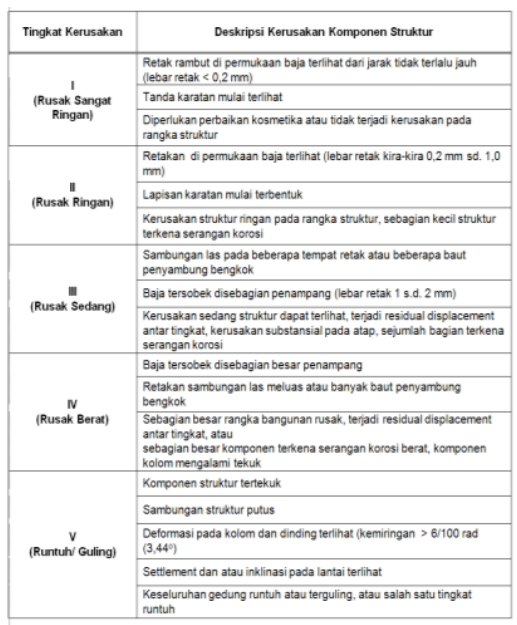

Tabel 3. Tingkat Kerusakan Komponen Struktur Kayu (Sjafei Amri, 2006)

\begin{tabular}{|c|c|}
\hline Tingkat Kerusakan & Deskripsi Kerusakan Komponen Struktur \\
\hline \multirow{2}{*}{$\begin{array}{c}\text { ' } \\
\begin{array}{c}\text { (Rusak Sangat } \\
\text { Ringan) }\end{array}\end{array}$} & $\begin{array}{l}\text { Retak rambut di permukaan kayu terlihat dari jarak tidak terlalu jauh } \\
\text { (lebar retak }<0,2 \mathrm{~mm} \text { ) }\end{array}$ \\
\hline & $\begin{array}{l}\text { Diperlukan perbaikan kosmetika atau tidak terjadi kerusakan pada } \\
\text { rangka struktur }\end{array}$ \\
\hline \multirow{2}{*}{$\begin{array}{c}\text { "I } \\
\text { (Rusak Ringan) }\end{array}$} & $\begin{array}{l}\text { Retakan di permukaan kayu terlihat (lebar retak kira-kira 0,2 mm sd. 1,0 } \\
\mathrm{mm} \text { ) }\end{array}$ \\
\hline & Kerusakan struktur ringan pada rangka struktur \\
\hline \multirow{3}{*}{$\begin{array}{c}\text { III } \\
\text { (Rusak Sedang) }\end{array}$} & $\begin{array}{l}\text { Sambungan kayu pada beberapa tempat retak atau beberapa bautpaku } \\
\text { penyambung bengkok }\end{array}$ \\
\hline & Kayu tersobek disebagian penampang (lebar retak 1 s.d. $2 \mathrm{~mm}$ ) \\
\hline & $\begin{array}{l}\text { Kerusakan sedang struktur dapat terlihat, terjadi residual displacement } \\
\text { yang kecil antar tingkat, kerusakan substansial pada atap, pelapukan } \\
\text { terjadi pada sebagian komponen struktur }\end{array}$ \\
\hline \multirow{3}{*}{$\begin{array}{c}\mathrm{IV} \\
\text { (Rusak Berat) }\end{array}$} & Kayu tersobek disebagian besar penampang \\
\hline & $\begin{array}{l}\text { Retakan sambungan kayu meluas atau banyak baut penyambung } \\
\text { bengkok }\end{array}$ \\
\hline & $\begin{array}{l}\text { Sebagian besar rangka bangunan rusak, terjadi residual displacement } \\
\text { antar tingkat, pelapukan terjadi secara meluas pada komponen struktur, } \\
\text { lepasnya hubungan antar komponen }\end{array}$ \\
\hline \multirow{5}{*}{$\begin{array}{c}\mathrm{V} \\
\text { (Runtuh/ Guling) }\end{array}$} & Komponen struktur tertekuk \\
\hline & sambungan struktur putus \\
\hline & $\begin{array}{l}\text { Deformasi pada kolom dan dinding terlihat (kemiringan > 6/100 rad } \\
\left(3,44^{\circ}\right)\end{array}$ \\
\hline & Settlement dan atau inklinasi pada lantai terlihat \\
\hline & $\begin{array}{l}\text { Keseluruhan gedung runtuh atau terguling, atau salah satu tingkat } \\
\text { runtuh }\end{array}$ \\
\hline
\end{tabular}

Tabel 4. Tingkat Kerusakan Bangunan (Sjafei Amri, 2006)

\begin{tabular}{|c|c|c|c|c|c|}
\hline \multirow{2}{*}{ No. } & \multirow{2}{*}{ URAIAN } & \multicolumn{4}{|c|}{ TINGKAT KERUSAKAN } \\
\cline { 2 - 6 } & RINGAN & SEDANG & BERAT & $\begin{array}{c}\text { RUNTUH/ } \\
\text { GULING }\end{array}$ \\
\hline 1 & $\begin{array}{l}\text { Berdasarkan } \\
\text { nilai penurunan } \\
\text { bangunan (s) }\end{array}$ & $\mathbf{s}<20 \mathrm{~cm}$ & $20 \mathrm{~cm}<\mathbf{s}<100 \mathrm{~cm}$ & $\mathrm{~s}>100 \mathrm{~cm}$ & \\
\hline 2 & $\begin{array}{l}\text { Berdasarkan } \\
\text { nilai kemiringan } \\
\text { bangunan }(\theta)\end{array}$ & $\begin{array}{c}\theta<(1 / 100) \\
\text { rad atau } \\
\theta<0,57^{\circ}\end{array}$ & $\begin{array}{c}(1 / 100) \mathrm{rad}<\theta< \\
(3 / 100) \mathrm{rad} \\
\text { atau } \\
0,57^{\circ}<\theta<1,72^{\circ}\end{array}$ & $\begin{array}{c}(3 / 100) \mathrm{rad}<\theta< \\
(6 / 100) \mathrm{rad} \\
\text { atau } \\
1,72^{\circ}<\theta<3,44^{\circ}\end{array}$ & $\begin{array}{c}\theta>(6 / 100) \\
\text { rad } \\
\text { atau } \\
\theta>3,44^{\circ}\end{array}$ \\
\hline 3 & $\begin{array}{l}\text { Berdasarkan } \\
\text { Kerusakan } \\
\text { Komponen } \\
\text { Struktur (D) }\end{array}$ & $\mathrm{D}<5$ & $5<\mathrm{D}<10$ & $10<\mathrm{D}<50$ & $\mathrm{D}>50$ \\
\hline
\end{tabular}

\section{Analisis dan Hasil Pengamatan Visual di Lapangan}

Komponen struktur yang ditinjau di lapangan secara pengamatan visual adalah:

a) Kolom

Kolom pada tingkat 1 mengalami kemiringan kekanan yang bervariasi dari 1,5 derajat s.d. 3 derajat (Kolom K1 s.d. K12) dengan kondisi fisik beton pembungkus mengalami retak-retak selebar $5 \mathrm{~mm}$ (Kolom K1 s.d. K3). Sedangkan Kolom K13 s.d. K27 dan semua kolom pada tingkat-2 masih dalam keadaan baik (lihat Gambar 3).

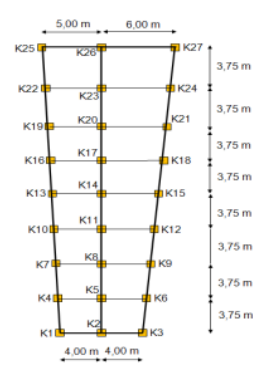

Gambar 3. Denah Kolom Tingkat-1 ( $\pm 8 \times 30$ m) (Dari Kanan Rumah Bpk. Gunadi dan Heriyanto) 


\section{Keterangan:}

- Kolom kode K1 s.d. K3: permukaan kolom bagian atas beton mengalami retak selebar $5 \mathrm{~mm}$ dan mengalami kemiringan 1,7 derajat (lihat Gambar 4 dan 5).

- Kolom kode K4 s.d. K12: permukaan kolom beton masih dalam keadaan baik, namun mengalami kemiringan sekitar 1,7 s.d. 3 derajat.

- Kolom kode K5 s.d. K27: permukaan kolom masih dalam keadaan baik dan kemiringan sangat kecil sekali $<1$ derajat.

- Kolom pada tingkat-2 permukaan betonnya tidak mengalami retak (lihat Gambar 6).

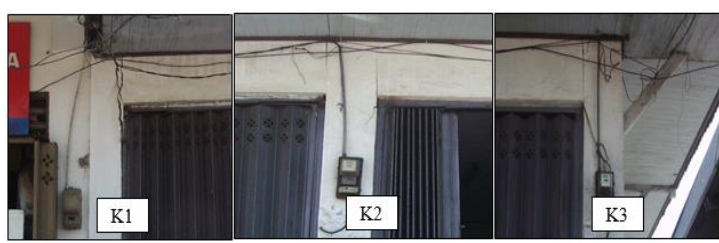

Gambar 4. Gambar kerusakan dan kemiringan kolom K1 K2, dan K3

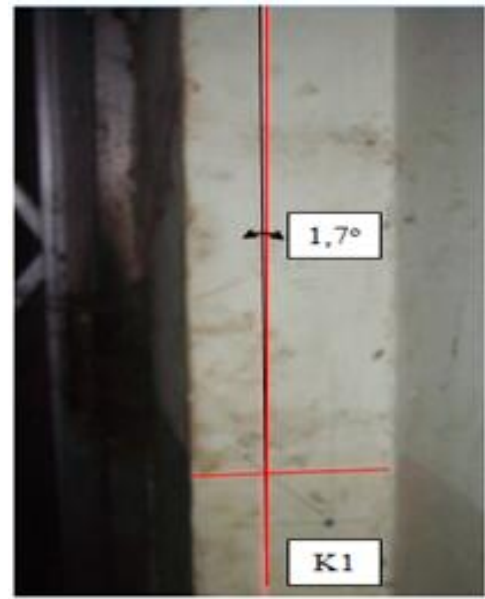

Gambar 5. Gambar kolom kode K1 yang mengalami kemiringan 1,7 derajat)

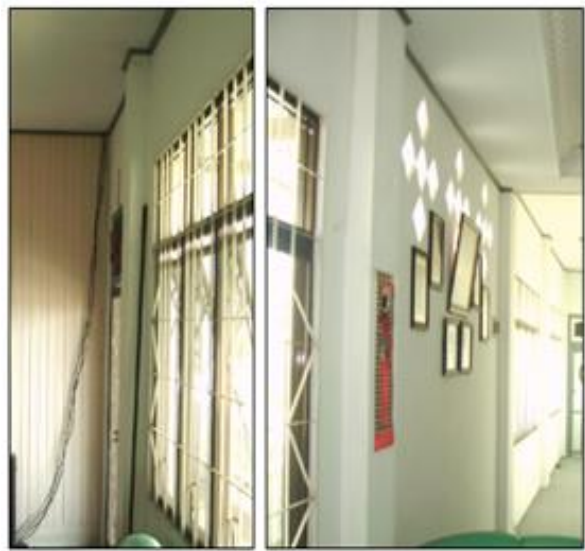

Gambar 6. Gambar kolom tingkat-2 yang masih baik

\section{b) Balok}

Balok memanjang dan melintang pada lantai 1 terbuat dari kayu ulin dengan ukuran $6 \times 12 \mathrm{~cm}$. Dari pengamatan visual pada bagian balok dibagian depan rumah Bapak Heriyanto kondisinya tidak mengalami kerusakan, sedangkan kondisi balok yang lain tidak dapat terlihat karena didalam plafond (lihat Gambar 7).
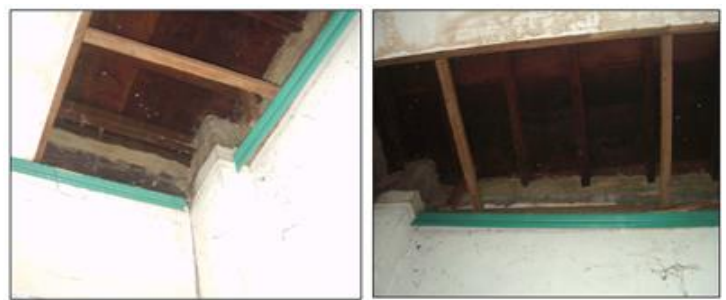

Gambar 7. Balok kayu ulin pada lantai 1 tidak mengalami kerusakan

\section{C) Pelat Lantai}

\section{Rumah Bapak Gunadi Utomo:}

Keramik 30×30 pada Pelat Lantai Dasar pada bagian muka sudah mengalami retak-retak, hal ini karena lantai sudah mengalami penurunan sekitar $3 \mathrm{~cm}$. Sedangkan pelat lantai 1 pada bagian depan dan belakang juga mengalami penurunan sekitar $1 \mathrm{~cm}$.

\section{Rumah Bapak Heriyanto:}

Keramik 30x30 pada Pelat Lantai Dasar pada bagian muka sudah mengalami retak-retak, dan lantai mengalami penurunan dengan perbedaan level lantai antara kolom K1 (perbatasan rumah Toko Harapan Jaya dengan Bapak Heriyanto) dan K2 (perbatasan antara rumah Bapak Gunadi dan Bapak Heriyanto) sekitar $11 \mathrm{~cm}$.

\section{d) Sistem Pondasi}

Sistem pondasi yang dipakai menggunakan amparan bantalan kayu ulin pada sepanjang bangunan dengan sambungan baut monel 5/8". Baut monel pada sambungan sudah mengalami karat karena terkena air laut. Dari hasil pengamatan balok suai/pengaku antar tiang hanya dipasang pada bagian tepi bangunan dan sebagian dipasang pada bagian tengah, selain itu takikan sambungan antara tiang dengan balok terlalu sedikit sehingga bangunan menjadi kurang kaku/ mudah bergerak (lihat Gambar 8).

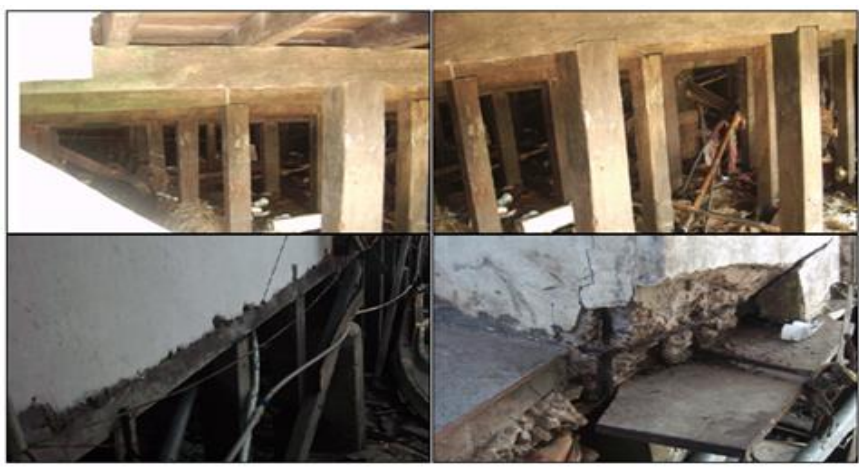


Gambar 8. Sistem Pondasi Tiang Kayu Ulin

\section{e) Struktur Kuda-Kuda Atap}

Struktur kuda-kuda terbuat dari kayu ulin dengan penutup atap terbuat dari genteng metal, terdapat retak pada dinding bagian depan dibawah atap-kudakuda dengan lebar retak $>1 \mathrm{~cm}$.

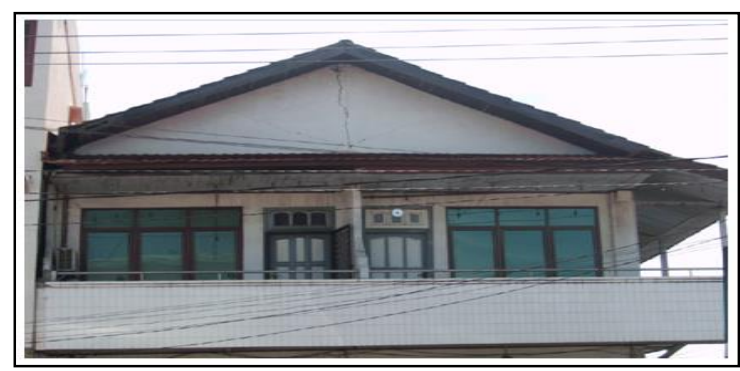

Gambar 9. Dinding bata dibawah atap mengalami keretakan

\section{f) Dinding Bata}

\section{Rumah Bapak Gunadi Utomo:}

Dinding terbuat dari plesteran bata pada tingkat -1 dan 2, dinding pada bagian muka pada bagian sudutsudut sudah mengalami retak. Dan dinding pada bagian kanan sepanjang $12 \mathrm{~m}$ sudah mengalami miring kekanan (lihat Gambar 10), sedangkan dinding dari $12 \mathrm{~m}$ sd. $30 \mathrm{~m}$ tidak mengalami kemiringan.

\section{Rumah Bapak Heriyanto:}

Dinding terbuat dari plesteran bata hanya pada tingkat -1 , sedangkan tingkat 2 dinding terbuat dari papan kayu. Hampir semua dinding bata mengalami retak yang > dari $5 \mathrm{~mm}$ (lihat Gambar 11).

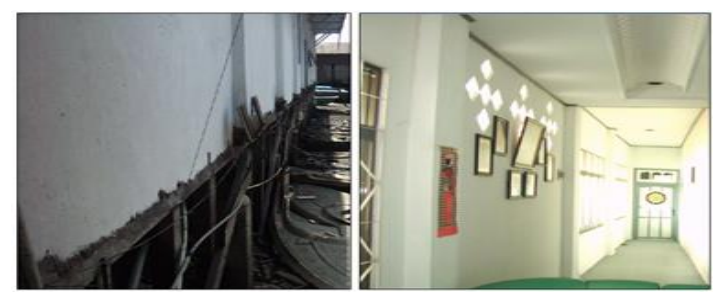

Gambar 10. Dinding bata bagian pinggir mengalami kemiringan, dan dinding bata pada tingkat-2 yang masih baik

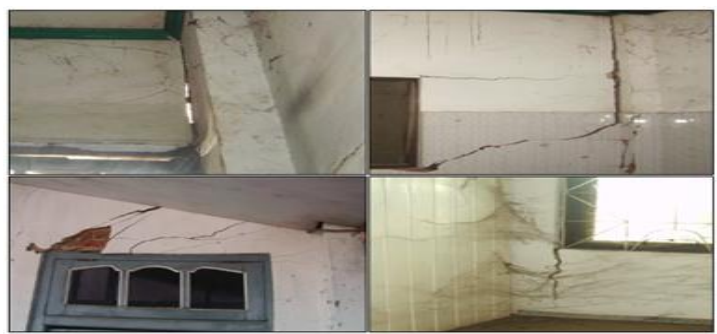

Gambar 11. Dinding bata mengalami keretakan yang parah

\section{g) Pergeseran Horisontal}

Terjadi pergeseran horisontal pada lantai 1 sebesar $10 \mathrm{~cm}$ kekanan pada bagian kolom depan (K1 s.d. K12), sedangkan pada tingkat 2 hanya terjadi pergeseran yang kecil ke kiri (lihat Gambar 12).

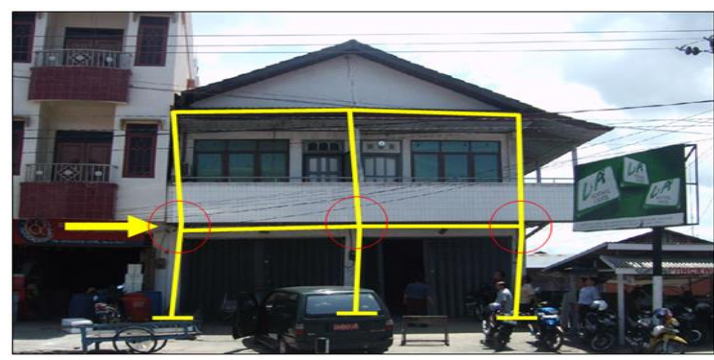

Gambar 12. Terjadi pergeseran horisontal pada tingkat 1 dan 2

\section{Hasil Analisis Pemeriksaan Struktur Bangunan}

Dengan berdasarkan pengamatan visual dan mendengarkan keterangan dari pemilik rumah, maka dapat dilakukan analisis sebagai berikut:

1) Kemiringan Bangunan

Bangunan mengalami kemiringan ke kanan sekitar 1,7 s.d. 3 derajat terutama pada bagian depan sepanjang $16 \mathrm{~m}$ kebelakang (kolom K1 s.d. K12) (berdasarkan hasil pengukuran alat sinar laser SL-2), sehingga termasuk kerusakan TINGKAT BERAT, sedangkan kolom yang lain kemiringan termasuk kerusakan TINGKAT RINGAN (lihat Tabel 4).

\section{2) Penurunan Bangunan}

Bangunan mengalami perbedaan penurunan terutama pondasi dibawah Kolom K1 s.d. K12 sekitar $11 \mathrm{~cm}$, namun masih dibawah $20 \mathrm{~cm}$, sehingga termasuk kerusakan TINGKAT RINGAN, sedangkan pondasi yang lain hanya mengalami penurunan yang kecil sehingga termasuk kerusakan TINGKAT RINGAN (lihat Tabel 4).

\section{3) Kerusakan Komponen Struktur}

Secara pengamatan visual terhadap komponen struktur Balok, Kolom, Pelat Lantai, kerusakan komponen struktur masih dalam kategori kerusakan TINGKAT RINGAN (lihat Tabel 4).

\section{4) Pergeseran horisontal bangunan}

Terjadi pergeseran horisontal pada lantai 1 sebesar $10 \mathrm{~cm}$ pada bagian kolom depan (K1 s.d. K12), sedangkan pada tingkat 2 hanya terjadi pergeseran yang kecil ke kiri, hal ini disebabkan oleh menyatunya sistem pondasi Toko Harapan Jaya dengan rumah Bapak Heriyanto sepanjang $16 \mathrm{~m}$ kebelakang sehingga menyebabkan tekanan horisontal pada tingkat 1 rumah Bapak Heriyanto.

5) Kestabilan Bangunan 
Berdasarkan ukuran bangunan terdapat perbedaan panjang bangunan pada bagian muka $8 \mathrm{~m}$ dan bagian belakang $11 \mathrm{~m}$, sehingga menyebabkan bangunan tidak simetris sehingga mengakibatkan bangunan secara geometrik kurang stabil. Selain itu kurangnya suai/pengaku pada tiang-tiang kayu pondasi.

\section{Kesimpulan}

Dari hasil analisis yang berdasarkan pengamatan visual (kualitatif) dan hasil pengukuran di lapangan dapat disimpulkan sebagai berikut:

1) Kemiringan Kolom K1 s.d. K12 termasuk Tingkat Kerusakan Berat. Sedangkan Kolom yang lain termasuk Tingkat Kerusakan Ringan (lihat Lampiran 1).

2) Penurunan bangunan termasuk Tingkat Kerusakan Ringan.

3) Kemiringan dan penurunan bangunan disebabkan turunannya pondasi pada perbatasan rumah Bapak Heriyanto dan Toko Harapan Jaya sehingga juga berefek terhadap bangunan rumah Bapak Gunadi.

4) Diberikan rekomendasi perbaikan dengan beberapa alternatif yang didiskusikan dengan beberapa pihak yang terlibat dengan mempertimbangkan tingkat keamanan dan biaya yang tersedia.

\section{Rekomendasi Perbaikan}

Rekomendasi alternatif perbaikan yang diberikan adalah hasil evaluasi kondisi lapangan yang ada, adalah sebagai berikut:

\section{Alternatif 1: (Lihat Gambar Lampiran 2)}

- Untuk kesempurnaan seluruh bangunan rumah Bapak Gunadi Utomo dan Bapak Heriyanto adalah dengan pembongkaran total kemudian dibangun kembali, namun sangat banyak mengeluarkan biaya.

- Desain dan gambar pelaksanaan dengan bangunan baru pada alternatif 1 ini disarankan dilakukan oleh konsultan perencana atau tenaga ahli perencana struktur yang berpengalaman dan memiliki sertifikat keahlian, agar diperoleh hasil desain yang baik dengan tingkat keamanan yang tinggi dan sesuai dengan peraturan perencanaan yang berlaku.

\section{Alternatif 2: (Lihat Gambar Lampiran 3)}

- Pembongkaran dan penggantian dengan bangunan baru sebagian pada daerah yang mengalami kemiringan dan penurunan bangunan seluas $8 \mathrm{~m} \times 16 \mathrm{~m}$, sedangkan bagian $16 \mathrm{~m}$ sd. 30 $m$ hanya perbaikan ringan.

- Pada bangunan yang tidak dibongkar, pada bagian kolom dipasang pengaku diagonal berupa pemasangan kawat sling/besi tulangan dengan pengencang pada lantai 1 dan 2 .

- Pada pondasi tiang ulin bagian tengah perlu ditambah balok suai/ pengaku yang terbuat dari kayu ulin, ukuran balok dan baut disamakan dengan suai bagian pinggir yang sudah ada.

- Dinding-dinding, pintu, kusen jendela pada bangunan yang tidak dibongkar yang telah mengalami kerusakan agar segera dilakukan perbaikan kosmetik/ penampilan.

- Desain dan gambar pelaksanaan dengan bangunan baru pada alternatif 2 ini disarankan dilakukan oleh konsultan perencana atau tenaga ahli perencana struktur yang berpengalaman dan memiliki sertifikat keahlian, agar diperoleh hasil desain yang baik dengan tingkat keamanan yang tinggi dan sesuai dengan peraturan perencanaan yang berlaku.

$\bullet$

\section{Alternatif 3: (Lihat Gambar 13 dan 14 pada} Lampiran 4)

- Melakukan perkuatan dengan profil baja antar kolom terutama pada daerah Kolom K1 s.d. K12 (pada kolom atas dan bawah), untuk mencegah kemiringan bangunan dan lepasnya sambungan kayu (penanganan perkuatan jangka pendek).

- Sedangkan antar kolom dipasang pengaku diagonal berupa pemasangan kawat sling/besi tulangan dengan pengencang pada lantai 1 dan 2 .

- Pada pondasi tiang ulin bagian tengah perlu ditambah balok suai/ pengaku yang terbuat dari kayu ulin, ukuran balok dan baut disamakan dengan suai bagian pinggir yang sudah ada.

- Apabila tidak ada perbaikan daya dukung pondasi pada bagian perbatasan rumah Toko Harapan Jaya dengan Bapak Heriyanto disarankan agar mengurangi beban yaitu dengan mengganti dinding bata yang ada dengan dinding bata ringan/ papan kayu seperti dilantai atas atau dibongkar sama sekali.

- Dinding-dinding, pintu, kusen jendela yang telah mengalami kerusakan agar segera dilakukan perbaikan kosmetik/ penampilan.

- Perbaikan pada alternatif 2 ini disarankan dilakukan oleh tukang atau kontraktor yang berpengalaman, agar diperoleh hasil perbaikan yang baik dengan tingkat keamanan yang tinggi.

\section{Referensi}

1 Departemen Pekerjaan Umum, Pedoman Mendirikan Bangunan Gedung (SKBI-1.3.53.1987 UDC: 69.002)

2 Sjafei Amri, Teknologi Audit Forensik, Repair dan Retrofit untuk Rumah \& Bangunan Gedung, Yayasan John Hi-Tech Idetama, Jakarta, 2006 


\section{Ucapan Terimakasih}

Penulis mengucapkan terimakasih kepada Bapak Heriyanto dan Bapak Gunadi Utomo sebagai pemilik bangunan yang telah banyak memberikan informasi mengenai materi tulisan ini. 